\title{
Comparative Analysis of Collaborative and Simulation Based Learning in the Management Environment
}

\author{
Mirjana Kljajić Borštnar
}

University of Maribor, Faculty of Organizational Sciences, Kidričeva 55a, 4000 Kranj, Slovenia, mirjana.kljajic@fov.uni-mb.si

\begin{abstract}
Purpose of the study is to compare two different approaches to the collaborative problem solving one in a highly controlled laboratory experiment: Optimisation of business politics using business simulator at different experimental condition which reflect different feedback information structure and one in a collaborative environment of the social media, characterised by non-structured, rule-free and even chaotic feedback information. Comparative analyses of participant's opinion who participate in experiments have been considered in order to find common characteristics relevant for group/collaborative problem solving. Based on these findings a general explanatory causal loop model of collaborative learning during problem solving was built.
\end{abstract}

Keywords: Group decision support, Information structure, collaborative learning, simulation model, social net

\section{Introduction}

Decision making is the most important process in human existence, being on an individual or societal level. More general, decision processes are immanent in all leaving beings at different level and in different context. The decision process can be regarded as complex problem solving: because it is a complex cognitive process comprised of systematic processing of knowledge and rationalisation, which should minimize the possibility of making a mistake (Wang, 1997). It is being described as a learning process that should provide sufficient knowledge for efficient problem solving and adaptation. Further on, such process can be efficiently supported by information systems, which basic role must be to provide the right information when needed. Nevertheless, information alone is not sufficient for successful decision making. The decisionmaking process often takes place in a social context. Decisions generated in organizational systems are not dependent on the individual decision of a subject, but rather on a group of individuals participating in decision making. The group as a whole understands the problem better (Hale, 1997), which should lead to synergistic effects. On the other hand, groups can be difficult to manage. There are problems of trust, conflicts, ... which can hinder the benefits of the group decision-making. Group support systems (GSS) are designed to manage these problems and enhance the positive effects of group work. Nevertheless, the positive effects of GSS are not unanimous in literature (Fjermestad, 2004). The problem lies in complexity of the process itself, with people as creative actors: there are problems with the level of facilitation, quantity, content, and frequency information feedback (Hsiao \& Richardson, 1999; Khalifa, Davison and Kwok., 2002; Rouwette, Größler and Vennix, 2004). The importance of process facilitation was shown by Kljajić Borštnar et al. (2011) and Limayem, Khalifa and Ma (2002). Furthermore, the study of Limayem et al. (2002) reported no difference between live and computer facilitation. Kim (2010) argued that the role of a leader is turned into a facilitator and that "... facilitation encourages uncooperative members to improve their participation in order to increase group cohesiveness." (Kim, 2010, p. 1569); therefore, the role of a facilitator is similar to the role of a teacher.

Managerial problems are usually complex and dynamic and are being described and vizualized in many ways in order to improve understanding and missperception of feedback. The simulation model described in this study is used as an explanatory tool for a better understanding of the decision process and/or for learning processes in enterprises and in schools. Many successful businesses intensively use simulation as a tool for operational and strategic planning as well as enterprise resource planning (ERP) (Schniederjans \& Kim, 2003; Muscatello, Small and Chen, 2003). Findings in literature (Forrester, 1969; Homer, 1996) emphasize that in a variety of industries real problems can be solved with computer simulation for different purposes and conditions. At the

Received: $9^{\text {th }}$ January 2012; revised $12^{\text {th }}$ April 2012; accepted $15^{\text {th }}$ July 2012 
same time, potential problems can be avoided and operative and strategic business plans may also be tested. From previous research on simulation-based problem solving ( ̌́ kraba, Kljajić and Leskovar, 2003; Škraba, Kljajić and Kljajić Borštnar, 2007; Kljajić Borštnar et al., 2011), we have come to some understanding about the nature of groups working together in a computer-supported virtual environment. Specifically, in the process of complex managerial problem solving supported by a simulation model and a GSS, the role of facilitator in a group process was shown, and the group belonging effect was empirically proven (Kljajić Borštnar et al., 2011). Further, the structure of feedback information was shown to have a great impact on the performance of the group. When the individual feedback information of a simulation model efficiently supported individual learning ( ̌̌kraba et al., 2003), the contribution of group information feedback was not as straightforward (Škraba et al., 2007). When group information feedback was provided in a controlled and facilitated process, it contributed to greater unity and better performance of the group members; in contrast, when it was freely accessible to the group members and the process was not facilitated, it caused the group to perform poorly and perceive the experiment poorly.

Recent developments in computer virtual communities and social media suggest that collaborative problem solving can be as or even more efficient than highly controlled computer virtual environments (Tapscott and Williams, 2006; Barabasi, 2002; Potter, McClure and Sellers, 2010). To be able to use collaborative problem solving while learning in educational, organizational and inter-organizational environments, we have to understand the environment and the learning processes. Our interest is focused on how people solve complex problems, and not the optimization of it, but the understanding of how it actually happens (Kljajić Borštnar, 2012).

The collaboration in a social media environment is not limited to a classroom, a set time and a small number of participants. Collaboration is considered to be any process of working with others with common objective. Similar to the description of a group learning process that may or may not result in a measurable learning outcome, but still displays the underlying group learning process (Lizeo, 2005), the collaboration process does not necessarily end up in creating values within specified spaces (Dillenbourg, 1999). This means that all collaboration tools available for supporting and promoting participative behaviour are not sufficient for the group to learn. In search of the concept of collaborative learning in the social media environment, Garrison, Anderson and Archer (2000), Freire (2000) and Wells (1999) argue that a critical discourse is of great importance within collaborative learning environments. Rosen (2007), in his book on the culture of collaboration, proposes ten cultural elements that support value creation: trust, sharing, goals, innovation, environment, collaborative chaos, constructive confrontation, communication, community, and value.

Purpose of the study is to compare two different approaches to collective problem solving. One in a highly controlled laboratory experiment, supported by a simulation model (Škraba et al., 2003; Kljajić Borštnar et al., 2011) and second, a task oriented collaborative problem solving in a social media environment (Kljajić Borštnar, 2012).

\section{Methodology}

Comparative analysis of participant's opinion from two different experiments has been considered in order to find general explanatory model of learning. Following experiments, denoted as Case 1 and 2 were described in (Škraba et al., 2003; Kljajić Borštnar et al., 2011) and (Kljajić Borštnar, 2012) respectively:

Case 1: Optimisation of business strategy using business simulator,

Case 2: Collaborative Learning in a Social Media Environment.

\subsection{Experiments description}

\subsubsection{Business simulator $-\mathrm{a}$ tool to improve learning process - Case 1}

In order to improve the method of teaching the »Modelling and simulation « course, and to explicate that simulation methods in management science are not only a tool for solving already known academic problems, but to support real-life problems, we built a business simulator. Students had to take active part in an experiment, solving the proposed business problem and report their results at the predefined times. They were motivated to regularly attend lectures and hands-on training, therefore similar level of participants' knowledge could be presumed. Furthermore, special care should be put on organizing the experiment, since the problem, task, environment and the business simulator have to reasonably reflect the real business situation and its utility.

Detailed description of the simulation model, developed by the system dynamics (SD) method, can be found in Škraba et. al (2003). The model consists of production, workforce and marketing segments. It was stated that product price positively influences income. However, as prices increase, demand decreases below the level it would otherwise have been. Therefore, the proper pricing that customers would accept can be determined. If marketing costs increase, demand increases above what it would have been as a result of marketing campaigns. The production system must provide the proper inventory level to cover the demand, which is achieved with the proper determination of the desired inventory value. Surplus inventory creates unwanted costs due to warehousing; therefore, these costs have to be considered. The number of workers employed is dependent on the production volume and workforce productivity, which is stimulated through salaries. Proper stimulation should provide reasonable productivity.

The participants in the experiment had the task of promoting a product on the market, whose life cycle is one year. The participants changed the parameter values via a user interface that incorporated sliders and input fields for adjusting the values. The goal of the participants was to maximize the criteria function, which was explicitly stated in order to achieve a proper level of experimental control with regard to the results obtained. The simulator enabled simultaneous observation of the system response for all variables stated by the criteria function during the experiment. 
In total, 147 subjects, senior university students randomly scheduled into three groups, participated in the experiment. The experiment was conducted under three experimental conditions:

$a_{0}$ ) Determination of strategy on the basis of a subjective judgment of the task

Under this condition, a subject had to make an individual judgment about the best possible strategy on the basis of the presentation of the model by the Causal Loop Diagram (CLD) and the stated Criteria Function. The participants had 30 minutes to determine the appropriate values of decision parameters and record their decisions on paper.

$a_{1}$ ) Individual decision-making supported by the simula-

\section{tion model}

Under this condition, each subject was supported by the simulation model, which provided feedback information about the anticipated business outcome. There was no limitation on the number of simulation runs a particular participant executed on the simulation model within the experimental time. After each predetermined time interval $(8+8+8+6$ minutes $)$, participants had to forward their selected business strategy to the network server and continue the search for the optimal business strategy. Participants had to make a final decision about the best business strategy and forward the selected decision parameter to the server after 30 minutes.

$a_{2}$ ) Decision-making supported by both the simulation model and group feedback information

The simulation model was connected to the GSS, which enabled the introduction of group feedback information into the decision process. Each individual subject was supported by the simulation model, which provided feedback information on the anticipated business outcome, and restricted interaction between subjects was enabled by GSS. Participants were able to examine the chosen business strategies (decision parameter values) of other participants in the decision group after the strategies were submitted to the network server. The participants could look into the "group's achievements" after the $8^{\text {th }}$, $16^{\text {th }}$ and $24^{\text {th }}$ minutes. There were no limitations on how many times they could seek group feedback. Group feedback information was presented in the form of a table, which contained input parameter values selected by each participant anonymously, and the average values of the parameters with the standard deviation.

The hypothesis that model application and group feedback information positively influence the convergence of the decision process and contribute to higher criteria function values was confirmed at the $\mathrm{p}=.01$ level. The results revealed that the final criteria function values were higher when group feedback information was introduced $\left(a_{2}\right)$ compared to the decision process that was based only on individual experience with a simulation model $\left(\mathrm{a}_{1}\right)$, and the lowest criteria function values were achieved on the basis of subjective judgment $\left(\mathrm{a}_{0}\right)$. However, we expected that the results gathered after the first eight minutes would not differ for the groups working with simulator $\left(a_{1}\right.$ and $\left.a_{2}\right)$ where the same conditions were in force in the first eight minutes: individual use of simulator. Because groups were randomized and homogenous, we expected no difference in participants' use of simulator. However, the frequency of simulator use in first eight minutes was significantly higher in Group $a_{2}$ than Group $a_{1}$. We repeated the experiment with conditions $a_{1}$ and $a_{2}$ (Škraba et. al, 2007) and the results were similar. In order to explain this phenomenon the pseudo Solomon FourGroup Experimental was designed (Kljajić Borštnar et al., 2011) wich permits testing of the interaction between pretest (in our case pretest can be interpreted as decision point at the 8th minute of experiment) and treatment (group information feedback). In this experiment we formed four groups: two were using only simulator, one with and the other without the faciliatotr. Two groups were using simulator accompanied with the group information feedback, one with and the other without the faciliatotr, therefore two new experimental conditions were added:

$a_{3}$ ) Continuous individual determination of strategy supported by a simulation model.

This condition assumed individual assessment of the decision maker, supported by simulator without facilitation, when determining the parameter values $\left\{r_{1}, r_{2}, r_{3}, r_{4}\right\}$ by maximization of the criteria function. At the end of the experiment, the subjects submitted their best-achieved parameter values to the network server.

$a_{4}$ ) Continuous individual determination of strategy supported by a simulation model plus GIF.

This condition assumed that subjects individually explored the simulation model and its behavior (Individual Information Feedback), but had additional information about the work of the group at their disposal at all times (GIF). Every simulation run (decision parameters $r_{i}$ ) was recorded in the database. The last performed simulation run of each subject along with the current average value of decision parameters $\left(r_{i}\right)$ were fed back as GIF. The subjects could access GIF in the form of a table by clicking the Group Information Feedback button on the user interface at any time. The participants' decisions were collected only once, at the end of the experiment, therefore the decision maker had 30 minutes time to experiment on the business simulator with the possibility of looking into the work of the group (GIF). At the end of the experiment, the subjects submitted their best-achieved parameter values to the network server.

Hypothesys that there is positive correlation between the frequency of simulation runs and the value of criteria function was accepted. This implies that the simulation model supports the individual learning on the trial and error basis. The hypothesis that an insight into group information feedback is influenced by the presence of facilitation was proven. More specifically, the information seeking behavior tends to be lower when facilitation is omitted. Furthermore, the interaction between treatment (GIF) and facilitation was shown to have an impact on the frequency of simulation runs.

All participants had to fill in the questionaire about their experience at the end of experiment. 


\subsubsection{Collaborative Learning in the Social Media Environment - Case 2}

The second case described the preliminary research of collaborative problem solving in a social media environment (Kljajić Borštnar, 2012). It is based on the assumption that collaborative learning can be efficiently supported in a rulefree and social media unstructured environment, and that it has a positive impact on the self-organizing of the group and thus contributes to problem solving and learning. Students had three weeks' time to complete the assigned study tasks using the Flowr social media (www.theflowr.com). Research was performed by observing them in the natural setting of the class conduction for the duration of three weeks. With observation methods and questionnaires, we aimed to answer the following research question: Does collaborative problem solving without formal structure and facilitation in the social media environment stimulate the self-management of the group?

The research took place in the 'natural environment' of a Computer Systems and Communication class. The class was comprised of 45 school hours of lectures (3 weeks), followed by 30 hours of practical training in the computer classroom (two weeks) plus individual students' work. Twenty-four undergraduate students of the class, aged between 20 and 23 years from the Faculty of Organizational Sciences, University of Maribor, participated in the study. At the beginning of the last week of lectures, students were presented a study task (a research topic) that they had to research and present at the end of the two weeks of practical training, thereby giving them three weeks of time (one week of lectures plus two weeks of practical training). Their work on the topic was not limited to the classroom; they were free to cooperate at the time of their own choosing. They were asked to form three groups with a maximum of 10 members per group was allowed. For the purpose of keeping the 'natural environment' intact, they were not told they were participating in a study. The role of the teacher (part of the research team) was to observe their work without interfering or facilitating it. The students were able to use the computer classrooms, but were also allowed to work from home or any facility and at time of their choice. Their task was to create a presentation of the research on topic selected by an individual group. Groups were given four topics from the class curriculum to choose from: 1) cloud computing, 2) collective problem solving, 3) information security, and 4) virtualization. The three groups selected the first three research topics.

Students received simple written and oral guidance for their assignment, explaining that they had to create groups that would research the selected topics, using the social collaboration service Flowr (www.theflowr.com). The instructions included instructions on how to use the Flowr service, and a description of the problem and the task. The task was part of the class curriculum; the topics are changed yearly according to the state of the art in the ICT field. The only new factor for the students was the use of a previously non-familiar social service.

After three weeks of collaborative work, students presented their work and reported their opinions through an anonymous questionnaire. The questionnaire was devoted mostly on the collaborative work. Statements formed key variables (constructs) researched in the study: general experiment quality, motivation, self-management of the group, trust, conflicts, absence of formal facilitation and structure, group satisfaction, and user experience. Two basic constructs, self-management of the group and the absence of structure and facilitation, and their association to motivation, trust and conflicts within the group was analyzed (Kljajić Borštnar, 2012).

We have provided evidence that less facilitation and structure is associated with grater ability to self manage $\left(r_{S}=\right.$ $-.483, p=.017)$. Further, the increase in motivation is associated with an increase in the ability of the group members to effectively self-organize $\left(r_{s}=.555, p=.006\right)$, and that a higher sense of trust is positively associated with an increase in the ability of the group members to effectively self-organize $\left(r_{S}\right.$ $=.455, p=.026$ ). Finally, the results revealed that there is no correlation between trust and formal structure and facilitation $\left(r_{s}=.177, p=.408\right)$. Findings suggest that perceived trust is not related to the amount of formal structure and facilitation.

\section{Results and Discussion}

The two experiments described above have several things in common. In both cases the participants were graduate students who were enrolled in the regular classes. Their tasks were to solve the stated problem. They were motivated to participate as their participation was rewarded within the final exam grade. However, there were differences which should be clearly stated:

- In case 1 the problem and the task were highly controllable in contrast to case 2 where the problem and task wouldn't give much control over the experiment (the result in Case 1 can be measured and analyzed quantitatively), the results in Case 2 cannot be objectively measured)

- The environment in Case 1 was controllable (limited time and place) in contrast to Case 2 where students had more time and no limits to their whereabouts.

- The main difference was still in facilitation of the problem solving process in Case 1 and no facilitation of Case 2.

In both cases our assumptions were based on the individual and collective learning during the problem solving process. According to Sterman (1994) learning can be described as a feedback process. Edmondson (1999) proposes that it can be observed as a feedback seeking behaviour on an individual level, but on a group or collective level it is very difficult to identify. The collective learning can be present without the measurable results and the results cannot always be attributed to the collective problem solving.

In Case 2 we were predominantly interested how trust and motivation affect the collaborative problem solving. Although sets of hypotheses that were answered in Case 1 and Case 2 provide answers in different contexts, the union of them gives an important view on organisation of collaborative problem solving process and therefore learning.

Case 1 (paragraph 2.1.1) in its nature represent learning supported by a simulation model with precisely defined and measurable decision task. Such an experiment has a 


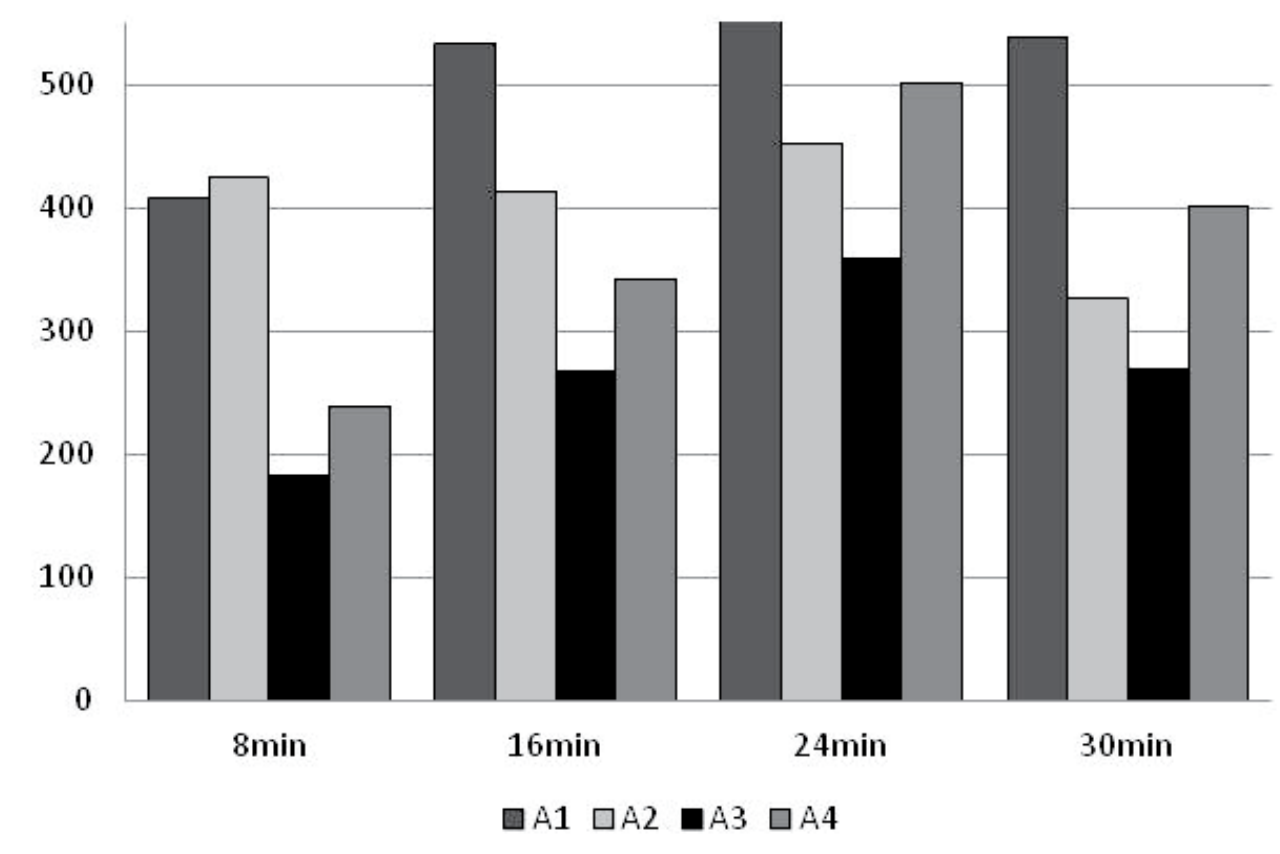

Figure 1: Individual feedback seeking behaviour - the use of simulation model

fixed decision-making structure. During the experiment we observed different types of feedback structure (interrupted goal oriented and continuous feedback information) and roles of the facilitator. Illustration of the impact of structure of group feedback information (goal oriented vs continuous) and the role of facilitator on the individual seeking behaviour is shown in Figure 1. We can observe from Figure 1 that the feedback seeking behaviour varies with time and with experimental condition. Two facilitated groups $\left(a_{1}\right.$ and $\left.a_{2}\right)$ showed higher interest in exploring the simulator compared to non-facilitated groups $\left(a_{3}\right.$ and $\left.a_{4}\right)$. Nevertheless, the trend in feedback seeking behaviour in time is consistant in groups receiving group information feedback $\left(a_{2}\right.$ and $\left.a_{4}\right)$ and in groups receiving individual information feedback only $\left(a_{1}\right.$ and $\left.a_{3}\right)$.

In Figure 2 the group feedback seeking behaviour for the two groups, where group information was introduced $\left(\mathrm{a}_{2}\right.$ and $a_{4}$ ) is presented. From Figure 2 it is evident that the facilitated group, $a_{2}(M=5)$ was significantly more active in seeking group information feedback compared to the non-facilitated group, $a_{4}(M=2)$. From Figure 2 we can observe that the facilitated group $\left(a_{2}\right)$ showed much more feedback seeking behaviour compared to group $\mathrm{a}_{4}$ where facilitation was omitted and the group information feedback was accessible at all time whereas in group $a_{2}$ it was accessible only after $8^{\text {th }}, 16^{\text {th }}$, and $24^{\text {th }}$ minute. Furthermore, from both figures (1 and 2) it can be observed that the presence of facilitator motivated the feedback seeking behaviour in both individual and group feedback condition. Also, it can be observed from both figures that participants sought the individual feedback more often than group feedback.

Besides the feedback seeking behaviour, we have tested the level of knowledge gained at the course "Modelling and simulation" of the participants, who participated in the simulation experiments and students, who didn't participate in the experiments by comparing grades received at the final examination (Kljajić Borštnar, 2010). Final exam grades (grades ranging from 1 to 5 - fail, 6 - 10 - pass) at the first attempt differ significantly in two groups: students who took part in the experiment $(\mathrm{M}=7.08, \mathrm{SD}=1.78, \mathrm{~N}=118)$, students attending regular classes without experiment $(\mathrm{M}=3.38, \mathrm{SD}=1.96, \mathrm{~N}$ =91). Experiment classes showed evidence that students were highly motivated to attend classes, which are not obligatory by default as opposed to the non-experiment classes, where students' attendance was rather low. It must be emphasized that the final grade of the course is derived from the student's individual project (40\%) and a written exam (60\%). The written exam consists of six standard question prepared in advance and selected by chance for all students, regardless of whether they had attend lectures or not. Therefore, the analysis of the results could be considered an unbiased one.

The participant's opinions about their involvement in the experiment were solicited with questionnaires. Participants filled in the questionnaires via a web application. Questions were posed in a form of a statement, and agreement to the statement was measured on a 7-point Likert type scale, where 1 represents very weak agreement, 4 a neutral opinion, and 7 perfect agreement with the statement.

Majority of the participants agreed on the general quality of the experiment (99\%). Of all the participants, $84 \%$ agreed that the use of simulator contributed to understanding of the problem. Agreement to the statement that they were motivated for problem solving among all the participants was $63 \%$. Further, students agreed that participating in the experiment had significant benefit to understanding the subject matter 


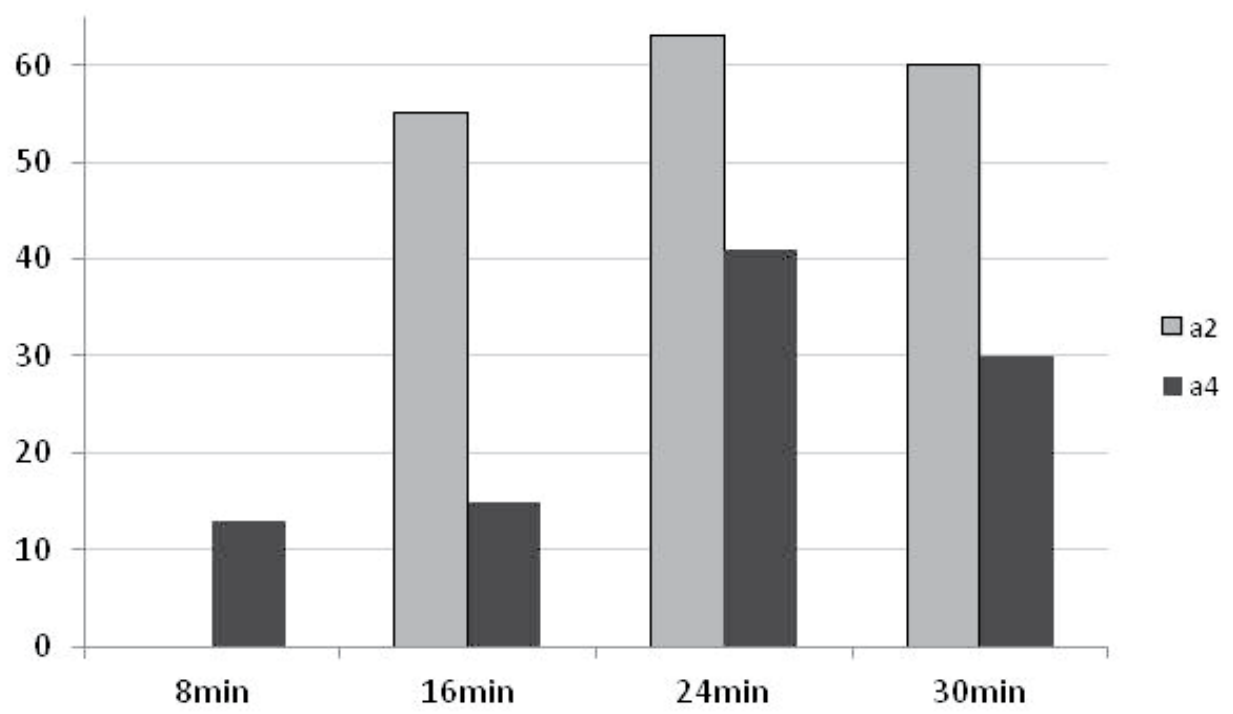

Figure 2: Group feedback-seeking behavior (insight into GIF per minute per subject) of groups $a_{2}$ and $a_{4}$ adapted from (Kljajić Borštnar et al., 2011)

(88\% agreed), and they identified simulator as an important aid to decision-making (92\% agreed). These are cross-group averages and represent the overall agreement to the statements.

We performed an ANOVA test to explore the differences in opinions among the four groups $\left(a_{1}, a_{2}, a_{3}\right.$, and $\left.a_{4}\right)$. The ANOVA test showed high agreement in opinion between groups as well. The groups' opinions differ significantly only in two questions: 4) simplicity of use of the simulator $(\mathrm{F}=3.067, \mathrm{p}=.031)$, and 5$)$ contribution of simulator to understanding of the problem $(\mathrm{F}=3.274, \mathrm{p}=.024)$, which can both be explained by different experimental conditions requiring slightly different user interface and thus different levels of man-computer communication.

In Case 2 (described in paragraph 2.1.2) students reported results on research topics freely, without facilitation, using social collaboration system Flowr. Common in both cases is the use of group collaboration technology and group problem solving with one difference: in the first case the task and technology were structured and controlled by an facilitator (part of research team) and in second case the task and technology were not structured nor controlled. The participants' opinion regarding the collaborative problem solving in the social media environment was solicited by the questionnaire (Kljajić Borštnar, 2012).

The majority of respondents agreed that the general quality of the experiment was good. They agreed (reported four or more points on the 5-point scale) that they were motivated for the work (60.87\%). More than $80 \%$ agreed that group had sufficiently self organized, i.e. members assigned roles, leadership and workload easily. Agreement on trust among members was assessed as good by more than $80 \%$ of respondents, while $66.67 \%$ of the respondents stated there were no conflicts in the group. Only $4.17 \%$ reported strong agreement and $16.67 \%$ reported agreement to the statement that there were conflicts within the group. This corresponds to the reports of conflicts within one group during the experiment, which led to the one group member transition to another group. A mere $8.33 \%$ strongly agreed and $37.5 \%$ agreed that facilitation and structure would contribute to better group work; $45.83 \%$ were neutral on this and only $8.34 \%$ disagreed on this. The vast majority of the respondents (more than $88 \%$ ) reported that they were satisfied with the work of the group. Further $45.83 \%$ of respondents reported neutral opinions about the user experience, half of them agreed to having had good user experience, while none reported negative user experiences.

Since the two cases questionaires consist of the same questions and the population is of the same background (senior students at the Faculty of Organizational Sciences, University of Maribor), we can perform a meta-analysis on this data. In Table 1 we present the corresponding questions along with the average value of agreement and standard deviation.

From Table 1 we can read the average and standard deviation values of responses on seven common questions from Cases 1 and 2. The responses from Case 1 were recoded from 7 to 5-point Likert type scale.

An independent-samples t-test was conducted to compare the effect of simulation experiment and social media experiment conditions. There was a significant difference in the scores for simulation experiment $(\mathrm{M}=4.5, \mathrm{SD}=0.701)$ and social media experiment $(\mathrm{M}=4.0, \mathrm{SD}=0.834)$ conditions regarding the perceived general experiment quality; $\mathrm{t}(140)=$ $3.082, \mathrm{p}=.002$.

On the question of problem presentation, the participants of the simulation experiment reported significantly higher scores compared to the participants of the social media experiment. T-test indicated that the mean score for the social media condition $(\mathrm{M}=3.29, \mathrm{SD}=1.042)$ was significantly different than the simulation experiment condition $(\mathrm{M}=4.43, \mathrm{SD}=$ $0.852) ; \mathrm{t}(139)=4.495, \mathrm{p}=.000$. 
Table 1: $t$-test for questionaire of the Case 1 and Case 2 participants opinion

\begin{tabular}{|c|c|c|c|c|c|}
\hline Statement & Case 1 & Case 2 & $\mathrm{t}$ & df & $\mathrm{p}$ \\
\hline \multirow[t]{2}{*}{ General experiment quality } & 4.50 & 4.00 & 3.082 & 140 & .002 \\
\hline & $(0.701)$ & $(0.834)$ & & & \\
\hline \multirow[t]{2}{*}{ Problem presentation } & 4.43 & 3.29 & 5.748 & 140 & .000 \\
\hline & $(.852)$ & $(1.042)$ & & & \\
\hline \multirow[t]{2}{*}{ Problem understanding } & 4.38 & 3.92 & 2.063 & 140 & .041 \\
\hline & $(.986)$ & $(1.100)$ & & & \\
\hline \multirow[t]{2}{*}{ Ease of use of the IT tool } & 4.76 & 2.71 & 13.536 & 140 & .000 \\
\hline & $(0.595)$ & $(0.999)$ & & & \\
\hline \multirow[t]{2}{*}{ Time for problem solving } & 4.06 & 4.42 & -1.228 & 140 & .221 \\
\hline & $(1.373)$ & $(0.830)$ & & & \\
\hline \multirow[t]{2}{*}{ Motivation for problem solving } & 3.72 & 3.54 & 0.634 & 140 & .527 \\
\hline & $(1.280)$ & $(1.141)$ & & & \\
\hline \multirow[t]{2}{*}{ Contribution of experiment } & 4.53 & 3.74 & 4.495 & 139 & .000 \\
\hline & $(0.725)$ & $(0.964)$ & & & \\
\hline
\end{tabular}

Note: Average

(Standard deviation)

Opinion was measured on 5 point Likert type scale

$\mathrm{N}=118$

Further, based on the t-test we have found significant differences between the two conditions on the question of ease of use of the ICT tool in question (simulator in Case 1 and social media tool Flowr in Case 2); $\mathrm{t}(140)=13.536, \mathrm{p}=.002$. As we can observe from Table 1, the Case 1 participants reported high agreement to the statement that the simulator was easy to use, where Case 2 participants disagreed to this statement. Similar, opinion on the overall contribution of the experiment to the class conduction, differ between the Case 1 and Case 2 participants. An independent-samples t-test was conducted to compare the effect of simulation experiment and social media experiment conditions. There was a significant difference in the scores for simulation experiment $(\mathrm{M}=4.53, \mathrm{SD}=$ $0.725)$ and social media experiment $(\mathrm{M}=3.74, \mathrm{SD}=0.964)$ conditions regarding the perceived general experiment quality; $\mathrm{t}(140)=3.082, \mathrm{p}=.002$.

The findings that simulation experiment participants perceived grater general experiment quality, better problem presentation and understanding than the participants of the social media experiment, can be explained by the facts that the first had an uniform video presentation of the problem, task and the tool and their role was highly determined, whereas the roles and organization of work of the Case 2 participants was left to their own freedom and creativity. Feedback seeking behav- iour, as one of the measurable criteria of learning behaviour, was shown to have been impacted by the level of freedom. In Figure 1 we have observed the feedback seeking behaviour of the simulation experiment participants. Particularly at condition $\mathrm{a}_{4}$ they showed less involvement in the problem solving when left to their own freedom to seek (or not) feedback information (individual and group). The participants at the social media experiment (Case 2) also showed some evidence of discomfort with the experiment. They perceived general experiment quality, problem presentation and understanding, the ease of use of the tool and assessment of overall contribution of the experiment to the class conduction is significantly lower than their colleagues in the highly regulated experiment. However, participants' opinions about the time for problem solving and motivation did not differ. This may suggest that given enough time to solve the problem and a common interest (task) in the social media environment, the groups were able to self-organize and understand the stated problem regardless the fact that they perceived problem presentation and understanding insufficient. However, it is interesting that the opinion about perceived motivation to solve the problem of participants at both experiments was regarded as neutral and it did not differ between the groups. 


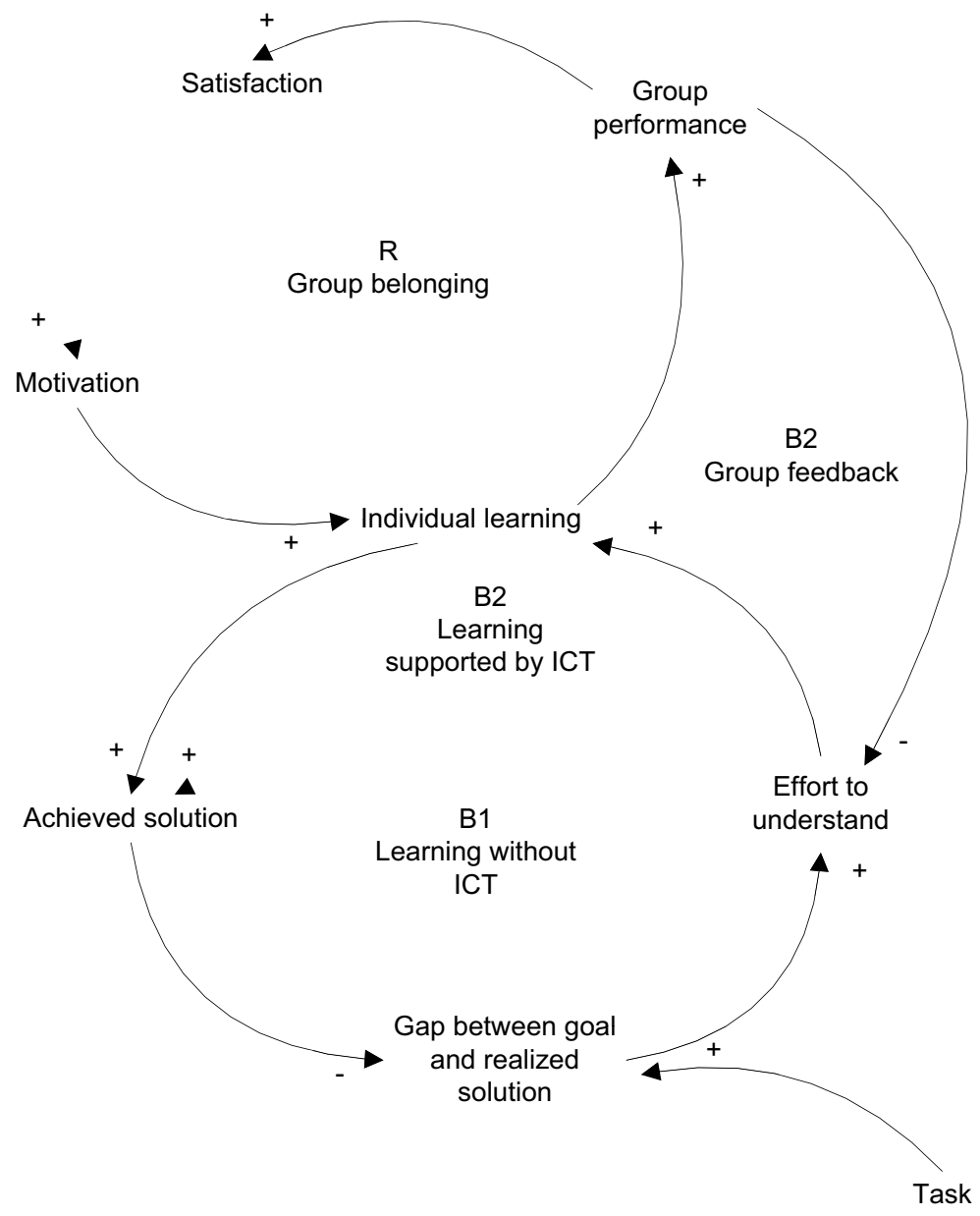

Figure 3: Causal loop diagram of group problem solving and learning adapted from (Kljajić Borštnar et al., 2011)

Common background of both experiments with regard to group problem solving and learning is presented in Figure 3 which represents generalisation of the model described in (Kljajić Borštnar et al., 2011).

On Figure 3 loop B1 represents heuristic problem solving without the aid of any tools except paper and pen. Loop B2 represents additional information in the problem solving provided by using ICT (simulation model/social media environment). The sum of both loops, B1 and B2, provides feedback information to participants in the process of problem solving and learning. B3 represents additional information provided by the group and its performance, and facilitates individual to understand the problem better. This we call the collaborative learning and group information feedback. In this loop different structure of information feedback is possible in Case 1 as well as in Case 2. Finally, loop R represents reinforcing loop which positively impacts motivation and satisfaction of an individual. However, gain of this reinforcing loop is proved to be strongly dependent on the structure of group information feedback (), quality of user interface. Furthermore, we showed that the time for problem solving is affected by the structure of information feedback (group a4 from Case 1 and Case 2) and level of freedom in the process of problem solving. Given enough time, the group would self-organize and creatively participate in problem solving (Case 2). On the contrary, when time is restricted, the group would show less feedback seeking behaviour, be less satisfied with the group performance and consequently be less motivated to participate in problem solving.

\section{Conclusions}

This paper analyzes experience in teaching of "Modeling and simulation" course using business simulation model as an experimental tool (Case 1), and collaborative problem solving phenomenon in a social media environment (Case 2) for senior students of the Faculty of Organizational Sciences, University of Maribor.

Case 1 in its nature represent learning based by means of simulation model with precisely defined (measurable) decision task. However, we observed different type of feedback structure to the participants and rolls of the facilitator. Such experiment has fixed structure in decision making. It was found that model application and group feedback information positively influence the convergence of the decision process 
and contribute to higher criteria function. More precisely, the results of the decision process gathered when group feedback information was introduced were better than in cases where the decision was based only on individual experience with a simulation model and the worst results were achieved on the basis of subjective judgment. However, group feedback and the facilitator are extremely important during complex problem solving. The results show that management students taking the course of Modeling and Simulation thought that application of the simulation model do contribute to a greater understanding of the problem, faster solution finding and greater confidence in participants.

In case 2 we analysed on trust and motivation in course of self managed of the group during problem solving. It was assumed that collaborative learning can be efficiently supported in a rule-free and social media unstructured environment, and that it has a positive impact on the self-organizing of the group and thus contributes to problem solving and learning. With observation methods and questionnaires, we aim to answer the following research question: Does collaborative problem solving without formal structure and facilitation in the social media environment stimulate the self-management of the group?

We developed generalised CLD model on Figure 1 that cover common background of both experiments with regard to group problem solving and learning. All participants in both cases agree that clear presentation of the problem motivates participants to find the solution. So, in the future, the use of realistic yet sufficiently simple business models is essential, if one wishes to close the gap between business processes understanding and the role of modeling and simulation in problem solving.

\section{Acknowledgment}

This research was funded by the Ministry of Higher Education, Science and Technology of the Republic Slovenija: Program No. P5-0018.

\section{References}

Barabási, A. (2002). Linked: The science of networks. Cambridge, MA: Perseus Publishing

Dillenbourg, P. (1999). Collaborative Learning: Cognitive and Computational Approaches. Advances in Learning and Instruction Series, Dillebourg, P. (ed.). Elsevier Science, Inc., New York.

Edmondson, A. (1999). Psychological safety and learning behavior in work teams. Administrative Science Quarterly, 44(2), 350-383. Retrieved 18 October 2009, from http://www.jstor. org/stable/2666999

Fjermestad, J. (2004). An analysis of communication mode in group support systems research, Decision Support Systems, 37, 239-263, http://dx.doi.org/10.1016\%2FS0167-9236\%2803\%2900021-6

Forrester, J.W. (1969). Urban Dynamics. Cambridge MA. Productivity Press.

Freire, P. (2000). Pedagogy of the oppressed (M. Bergman Ramos, Trans.), New York: Continuum International Publishing Group.
Garrison, D. R., Anderson, T. \& Archer, W. (2000). Critical inquiry in a text-based environment: Computer conferencing in higher education. The Internet and Higher Education, 2 (2-3), 1-19.

Hale, R., \& Whitman, P. (1997). Practical Problem Solving and Decision Making. Kogan Page: London.

Homer, B.J. (1996). Why we iterate: Scientific modeling in theory and practice. System Dynamics Review, 12(1), 1-19, http://dx.doi.org/10.1002\%2F\%28SICI\%291099$1727 \% 28199621 \% 2912 \% 3$ A $1 \% 3$ C $1 \% 3$ A\%3AAID SDR93\%3E3.0.CO\%3B2-P

Hsiao, N. \& Richardson, G. P. (1999). In search of theories of dynamic decision making: a literature review. In 17th International Conference of the System Dynamics Society, Wellington, New Zealand. Retrieved 19 February 2010, from http://www.systemdynamics.org/conferences/1999/PAPERS/PLEN16.PDF

Khalifa, M., Davison, R., \& Kwok, R. C. W. (2002). The effects of process and content facilitation restrictiveness on GSS-mediated collaborative learning. Group Decision and Negotiation, 11, 345-361, http://dx.doi.org/10.1023\%2FA\%3A1020449317854

Kim, Y. (2010). Supporting distributed groups with group support systems: a study of the effect of group leaders and communication modes on group performance. In Strategic Information Systems: Concepts, Methodologies, Tools, and Applications, Hunter MG (ed.). Hershey, PA: Information Science Reference; 1559-1572.

Kljajić Borštnar, M., Kljajić, M., Škraba, A., Kofjač, D. \& Rajkovič, V. (2011). The relevance of facilitation in group decision making supported by a simulation model, System Dynamics Review, 27(3), 270-293, http://dx.doi.org/10.1002/sdr.460

Kljajić Borštnar, M. (2012). Towards understanding collaborative learning in the social media environment. Organizacija, 45(3), 100-107, http://dx.doi.org/10.2478/v10051-012-0010-8

Kljajić Borštnar, M., Rajkovič, V., Kljajić, M., Škraba, A. \& Kofjač, D. (2010). Simulation based learning aboutcomplex management systems : a simulation experiment. In: Final program and book of abstracts. [s. 1.]: Institute for Systems and Technologies of Information, Control and Communication, INSTICC: 50.

Limayem, M., Khalifa, M. \& Ma, S. (2002). Human versus automated facilitation in the GDSS context. In Proceedings of the 2002 IEEE International Conference on Systems, Man and Cybernetics, Vol. 5: Hammamet, Tunisia, 6-9 October, http:// dx.doi.org/10.1109\%2FICSMC.2002.1176365

Lizeo, E. (2005). A Dynamic Model of Group Learning and Effectiveness, System Dynamics Society Conference 2005, Boston, USA. Retrieved 21 June 2012, from http://www.systemdynamics.org/conferences/2005/proceed/papers/LOFDA177. pdf

Muscatello, J.R., Small, M.H. \& Chen, I.J. (2003). Implementing enterprise resource planning (ERP) systems in small and midsize manufacturing firms. International Journal of Operations \& Production Management, 23(8), 850-871, http://dx.doi. org/10.1108/01443570310486329

Potter, A., McClure, M. \& Sellers, K. (2010). Mass collaboration problem solving: A new approach to wicked problems. 2010 International Symposium on Collaborative Technologies and Systems, 398-407. IEEE, http://dx.doi.org/10.1109/ CTS.2010.5478486

Rosen, E. (2007). The Culture of Collaboration: Maximizing Time, Talent and Tools to Create Value in the Global Economy, Red Ape Publishing.

Rouwette E. A. J. A. Größler, A. \& Vennix, J. A. M. (2004). Exploring influencing factors on rationality: a literature review of dynamic decision-making studies in system dynamics. Systems Research and Behavioral Science, 21(4): 351-370, http://dx.doi.org/10.1002\%2Fsres.647 
Schniederjans, M.J. \& Kim, G.C. (2003). Implementing enterprise resource planning systems with total quality control and business process reengineering - Survey results. International Journal of Operations \& Production Management, 23(4):418429, http://dx.doi.org/10.1108/01443570310467339

Škraba, A., Kljajić, M. \& Leskovar, R. (2003). Group exploration of system dynamics models - Is there a place for a feedback loop in the decision process? System Dynamics Review, 19: 243-263, http://dx.doi.org/10.1002/sdr.274

Škraba, A., Kljajić, M. \& Kljajić Borštnar, M. (2007). The role of information feedback in the management group decisionmaking process applying system dynamicss models. Group Decision and Negotiation, 16:77-95, http://dx.doi.org/10.1007/ s10726-006-9035-9

Sterman, J.D. (1994). Learning in and about complex systems. System Dynamics Review, 10: 291-330, http://dx.doi.org/10.1002/ sdr.4260100214

Tapscott, D. \& Williams, A.D. (2006). Wikinomics: How mass collaboration changes everything. New York: Penguin
Wang, H. (1997). Knowledge level analysis of group decision support systems. Expert System with Application, 13, 155-162, http:// dx.doi.org/10.1016\%2FS0957-4174\%2897\%2900016-X

Wells, G., (1999). Dialogic Inquiry. Cambridge: Cambridge University Press.

Mirjana Kljajić Borštnar holds a Ph.D. in Organizational Sciences from the University of Maribor. Her research work covers expert systems, multi-criteria decision-making, and Information Systems development methods. She holds a position of an Assistant Professor and is a member of Laboratory for Decision Processes and Knowledge-Based Systems. Her recent research work is focused on experiments with decision groups applying system dynamics simulators in experimental, real and interactive learning environments. She is the author and co-author of several scientific articles published in recognized international journals including Group Decision and Negotiation and System Dynamics Review. 